\title{
Are TQM principles supporting innovation in the Portuguese footwear industry?
}

\author{
Ana Abrunhosa*, Patrícia Moura E Sá \\ Faculty of Economics, University of Coimbra, Avenida Dias da Silva, 156, 3004-512 Coimbra, Portugal
}

\begin{abstract}
The relationship between total quality management (TQM) and innovation is complex. Literature suggests that conflicting arguments exist and that the impact of TQM on innovation depends both on the specific quality management elements under consideration and on the type of innovation. In this research, our goal is to analyse at what extent the introduction of TQM is indeed supporting innovation in the Portuguese footwear industry. Since this is a mature industry, whose traditional competitive base is disappearing and where familiar to medium units dominate, our emphasis is on the study of the organisational requirements to adopt constant changes in process technology. This study is based on empirical data collected from a set of firms by means of a survey instrument, especially developed with this purpose, after an extended contact with the industry where case studies and interviews were conducted with carefully selected organisations and sector experts. Findings give support to the view that in fact TQM principles have a positive association with the adoption of technological innovation. Yet, both the prevalence of features of the mechanistic model and the lack of maturity of most initiatives in the Portuguese footwear firms restrains the role of TQM in supporting innovation.
\end{abstract}

(C) 2007 Published by Elsevier Ltd.

Keywords: TQM; Technological innovation; Portuguese footwear industry

\section{Introduction}

There is a current and open debate in the literature concerning the contribution of total quality management (TQM) to innovation. Several studies have been analysing at what extent organisations that implement TQM principles and approaches tend to be more innovative (Prajogo and Sohal, 2001, 2006a, b; Singh and Smith, 2004; Molina et al., 2007; Sá and Abrunhosa, 2007). As a complex management philosophy, TQM embraces a set of principles, which tend to have a different impact depending on the type of innovation considered. All in all, it has been suggested that some TQM elements, i.e. the ones which correspond to its "soft" components, are potential enablers of incremental innovation (Prajogo and Sohal, 2004).

When looking at the relationship between TQM and innovation, most studies (Prajogo and Sohal, 2004,

\footnotetext{
*Corresponding author. Tel.: + 351239790573 ; fax: + 331239790514.

E-mail addresses: ampa@fe.uc.pt (A. Abrunhosa),pmourasa@fe.uc.pt (P. Moura E Sá).
}

2006a, b; Singh and Smith, 2004) aggregate firms that belong to different industries. In doing so, they might well be ignoring that both TQM and innovation are "path dependent", i.e. they are cumulative processes, which reflect the specificities of the contexts in which they occur. Moreover, innovation clearly depends on numerous factors and the contribution of TQM is better acknowledged when a single industry is considered.

To overcome some of these limitations, we decided to focus our research on a single industry, thus ensuring that all the firms analysed face a similar environment.

An additional drawback found in the literature concerns the way TQM and innovation are conceptualised and operationalised (Cameron and Barnett, 2000; Flynn and Saladin, 2001; Saraph et al., 1989). Often, the elements of TQM taken into consideration are not clearly identifiable. This is a major problem, since, as Prajogo and Sohal (2001, 2004) argue, different TQM principles can have dissimilar impacts on innovation. If that holds for TQM, the same applies for innovation. In fact, innovation is a multidimensional phenomenon (incremental vs. radical, 
technological vs. administrative, product vs. process), but many studies do not clarify which dimensions they consider (e.g. Singh and Smith, 2004). In our study, we have made an effort to clearly define and delimitate these concepts.

With the aim of contributing to the discussion over the link between some TQM principles and certain types of innovation, our study looks in particular at the effects that some "soft" TQM practices have on process technological innovation in the Portuguese footwear industry.

Several reasons explain why we focused our study in the Portuguese footwear industry. Firstly, this sector represents more than $5 \%$ of the value of the Portuguese exports of goods (APICCAPS, 2003) and, worldwide, the Portuguese footwear sector has a share of $3.4 \%$ of the exports value (United Nations, 2003). In this context, Portugal is a major player, being in the 4th position as a leather exporter (in which the Portuguese sector is specialised). Secondly, the sources of competitive advantage for the Portuguese footwear industry have changed over the last decade, making it a typical example of a mature industry where low costs are no more a competitive advantage and innovation became a top priority. In fact, if, in the 1970s and 1980s, the industry grew based on the low labour costs and on economies of scale based on large volume, in the 1990s this was not possible anymore. Throughout the 1990s, many global buyers of footwear moved their operations and orders from Portugal to Asia and Eastern Europe. While not discarding, by any means, the importance of cost, it is fairly obvious that Portuguese companies can only remain in the market and prosper by pursuing a differentiation strategy, supported by innovation. Pressures to innovate came also from the demand-side. Indeed, in developed countries, shoes have increasingly become a life-style purchase, with an increase in orders for urgent and smallsized batches of fashionable products (with higher variety in models and colours) and a decrease of orders for large batches of standardised shoes with long lead times.

Taken together, these changes forced Portuguese companies to adopt technological innovations at the shopfloor level, which are essential to shift from the production of large batches to small batches and to constantly develop and produce fashionable shoes. Additionally, being a mature industry, technological innovations are essentially incremental rather than radical (Freel, 2003). In this regard, and considering that the basis for competitiveness is more and more associated with intangible factors - such as time-to-market, customisation and the provision of additional services - , organisational innovation is becoming crucial and demands, among other aspects, the introduction of a management philosophy that puts the customer, the workers and continuous improvement at the core of everything that an organisation does.

Our findings suggest that the "soft" elements of TQM we have considered are in general positively associated with technological process innovation adoption. Communication and the implementation of supportive people management practices were in this regard particularly relevant.
Benefiting from the general small dimension of the firms and from the fact that many are family owned and run, communication is high and easy, both vertical and horizontal. That seems to be contributing to information dissemination, commonly regarded as key to innovation adoption. Additionally, the suggested supportive people management practices, namely continuous education and training and the use of appropriate performance appraisal schemes, is also significantly associated with the adoption of innovation, corroborating the idea that more qualified and motivated shopfloor employees are important innovation drivers.

On the contrary, certain TQM principles, such as autonomy and consultation, do not reveal the expected association with innovation. Once again, industry characteristics can explain this outcome. In fact, in these firms decisions tend to be highly centralised, operators have low level of qualifications and mainly follow instructions, thus having little discretion and control over job-related decisions.

The conclusions of this study carried out in the Portuguese footwear industry can be useful to other countries in which this sector is traditionally important (e.g. Spain and Italy), as well as to other mature industries (e.g. textile and garment) in developed countries that face the same kind of competitive pressures. Therefore, our study can be regarded as a benchmark.

Furthermore, while most research on organisational theory, and particularly on the field of management of innovation, focuses on either new ventures in hightechnology sectors or on big companies, our study analyses small- and medium-sized firms in mature markets, which are considerably understudied in the literature considering their prevalence and economic importance.

The remainder of this paper is structured as follows: Section 2 reviews the general issues within the relationship between TQM and innovation in order to help us to reach the definitions of the main concepts used in this research and to put forward the hypotheses that guide the study. Next, in Section 3, the research goals and methodology are justified, including the design of the research instrument, the data collection procedures and the process of construct validation. Section 4 presents and discusses the main results. Finally, in Section 5, we analyse the main contribution of our research to the current debate in the field and give some indications of possible future developments.

\section{Theoretical background}

\subsection{Total quality management: definition and key principles}

Since the 1930s, quality management has raised considerable interest among researchers and practitioners.

From a taxonomy standpoint, TQM emerged in the 1980s but its roots go back to the scientific management principles of the 1920s (McAdam, 2000). Since then, 
however, TQM evolved from a predominantly narrow and mechanistic approach (Hermel, 1997, cited in McAdam, 2000), with quality being essentially regarded as a technical and production matter, to a more subjective and social approach, which considers TQM as a comprehensive management philosophy, embracing all the aspects of the organisation and involving its entire workforce, as well as its customers and suppliers (Dale et al., 1997; Mehra et al., 2001).

As Weick (2000, cited in Cameron and Barnett, 2000) points out, "quality is a diffuse, multidimensional construct, and little consensus exists regarding how it can be measured or operationalised". Although different researchers emphasise different dimensions of TQM, the following definition covers the main elements rose by the quality gurus and will be adopted here:

Total quality management is a management philosophy that fosters an organisational culture committed to customer satisfaction through continuous improvement (Kanji, 2002).

According to Spencer (1994), TQM does not constitute by itself a completely new paradigm, rather captures characteristics from distinct organisational models - mechanistic, organic and cultural - and amplifies them by providing a methodology for use (see Table 1).

Both the mechanistic model and TQM conceive organisations as goal-attainment devices (Spencer, 1994), but TQM recognises the environment as a vital source of resources and constraints.

Treating organisations as organisms is associated with the systems perspective (Jackson, 1991). The impact of the organic model can be found on the tendency of TQM to see organisations as systems, which in order to operate effectively need to have a purpose. Accordingly, organisations are made of highly interdependent parts that must work together to achieve the system's overall aim. The contingency approach to TQM, which states that to be successfully implemented TQM must be properly aligned with the particular organisational environment, strategies and design (Moreno-Luzón and Peris, 1998), has also its roots on the organic model developed in the 1950s.

In summary, TQM is described in this paper as a management philosophy made up of three key elementscustomer focus, people involvement and continuous improvement-which we present next.

\subsubsection{Customer focus}

TQM is, by definition, a customer-oriented philosophy (Mehra et al., 2001). Delight the customer involves, first of all, identifying who the customers are. Both external customers and internal customers must be considered. Because expectations are dynamic (Ahire et al., 1996), an organisation must be in close contact with its customers (Dean and Bowen, 1994) and have in place mechanisms to determine their expectations and measure their levels of satisfaction.

\subsubsection{People involvement}

TQM stresses the importance of involving everyone in the process of "customer driven" continuous improvement, which can only happen if all staff is given the space and responsibility to innovate and make decisions. This generally implies a new job design, which encompasses more autonomy and flexibility in performing daily activities.

Table 1

TQM and organisational models (Adapted from Spencer, 1994)

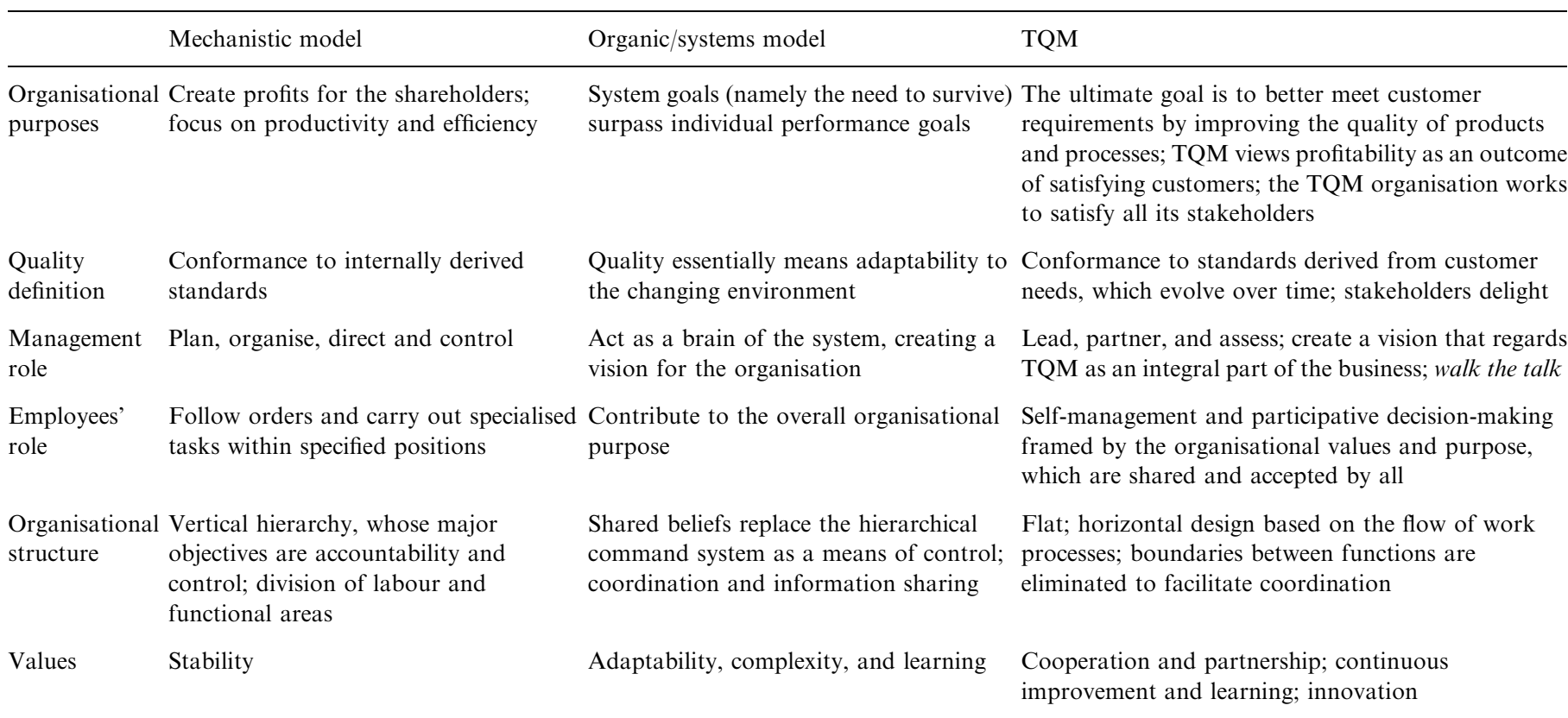


TQM assumes that people naturally want to do a good job and will try to improve as long as they are provided with the necessary training and resources (Grant et al., 1994; Hackman and Wageman, 1995), while feeling they are being sufficiently rewarded for their efforts, under appropriate appraisal schemes. In fact, TQM requires a new set of competences. The changes in working practices demanded by TQM are only possible if supportive people management practices are implemented.

Moreover, people perform better if they work in a cooperative and friendly environment. The nature of most organisational problems requires a high degree of interfunctional interaction. Therefore, communication and teamwork should be encouraged and developed.

\subsubsection{Continuous improvement}

Continuous improvement requires an organisational culture that constantly encourages members to innovate, minimises fear and provides them with a rich and diverse set of tools.

Improvement comes from learning from mistakes, implementing corrective actions and trying new things, based on the lessons learned from the past. Thus, improvement opportunities must be continuously identified and feedback collected from external and internal customers to continuously measure progress towards the goals.

\subsection{Innovation: definition and major enablers}

Innovation is widely acknowledged as key to economic development, since it potentially leads to productivity and competitive gains.

The European Commission defines innovation as "the renewal and enlargement of the range of products and services and the associated markets; the establishment of new methods of production, supply and distribution; the introduction of changes in management, work organisation, and the working conditions and skills of the workforce" (CEC, 1995, p. 688). In line with this, we will use the term "innovation" as embracing the creation or application of new knowledge, or the recombination of existing knowledge, to generate value through the introduction of products, processes, markets or organisational forms, new or substantially improved to the adopting firm.

The definition of innovation we have adopted here is wide enough to include both inventions and adoptions. Thus, innovation does not exclusively result from R\&D; it is a multidimensional process, with multiple sources, most of the times coming from complex interactions among individuals, organisations and the institutional setting (systemic model). Looking at the big picture, it is usual to classify innovations as radical or incremental, although, what we have in fact is much more a continuum. At one extreme, we can find those innovations that are so great that they result in a fundamental change in the very nature of a business, whereas, at the other extreme, there are some innovations that are so minor they are barely perceived as changes (Gilbert, 1994).

This classification can be done at two distinct levels: globally (for the whole economy/industry) or individually (to the firm). If the first perspective is adopted, radical innovation represents the creation of a novelty with commercial-value to the world (if it happens in clusters then it may even originate the emergence of a completely new industry (Freeman and Perez, 1988)). In line with this, incremental innovation comes in the form of improvements and adaptations that occur as radical innovations are diffused in the economic system (technological trajectory). On the other hand, when the second perspective is adopted, the dominant criterion in classifying innovations is the impact of the innovation to the firm: if the innovation challenges the dominant practices and knowledge, then it can be considered as radical.

For the purpose of the current study, we have adopted the global perspective. Accordingly, radical innovation usually comes from R\&D activities and is translated into new products and/or processes, opening new markets and new investment opportunities. Incremental innovation, even if it may take place within $R \& D$ departments, typically builds on existing technologies, products, services, or routines and modifies them to some degree. This takes place as a result of learning by doing (Arrow, 1962), learning by using (Rosenberg, 1982), and learning by interacting (Lundvall, 1985). Besides resulting from informal learning processes in daily routine activities, incremental innovation occurs when firms adopt and use new products, processes, or organisational forms created/ developed by others in a way that fits their own needs and specificities.

Although incremental innovations may be regarded as minor, their cumulative effect tends to be quite impressive. Yet, if that is to occur, the innovation process must be properly managed and nurtured.

There are multiple sources of technological innovation. Apart from R\&D activities, other sources are rated high: purchase of equipment, design, proposals from employees, customer requests and staff training (Baldwin and Johnson, 1996). Considering the Portuguese footwear industry, it is possible to state that technologies are mature and technological innovation mainly results from the adoption of technologies that already exist in other industries or in the same industry in other countries. However, due to the close relationship between equipment and systems' suppliers and users, innovation takes place in a way that considers the specific conditions of the adopting firms. This clearly shows the importance of these partnerships to the technological innovation process in this sector.

\subsection{The impact of TQM on innovation: supporting and detrimental elements}

TQM was previously defined (see Section 2.1) as a philosophy that stresses customer focus, employee involvement 
and continuous improvement. In this section, we will briefly discuss the impact of each of these elements on innovation. This discussion provides the grounds for our theoretical framework and will guide the hypothesis building.

The role of customer focus in driving innovation has been widely discussed. In fact, contradictory arguments exist. To some authors (e.g. Wycoff, 2003), customer focus is the push, encouraging organisations to consistently search for new customer needs and expectations, develop and introduce new products as a continual adaptation to the market's changing needs, and helping to ensure that innovations create customer value. To others (e.g. Slater and Narver, 1998, cited in Prajogo and Sohal, 2004), customer focus is likely to inhibit significant innovation, since the process is constrained by what the customers want and, at some extent, expect, thus making the organisation too reactive. The rationale behind this argument is that customers are unable to articulate their future needs beyond current consumption experiences (Atuahene-Gima, 1996).

The TQM philosophy is built on the belief that firms should encourage all of their employees to continuously search for new ideas and improvements. In this regard, it is widely acknowledge that teams play an important part in innovation, especially linked to creativity and knowledge management (McAdam, 2004; Molina et al., 2007). Since innovation involves "the cumulative or path dependent creation of new knowledge, or novel recombination of existing knowledge" (Freel, 2003), it is essentially concerned with learning. Accordingly, the TQM emphasis on education and training complemented with appropriate performance appraisal schemes (i.e. the existence of supportive people management practices), as suggested in most TQM models, is an important driver of creativity and innovation.

Analysing the relationship between continuous improvement and innovation is particularly challenging. To some extent, continuous improvement, by calling to the constant upgrading of products and processes, is by itself a form of innovation. The main question that dominates the debate is, however, the extent to which continuous improvement, by stressing a level of change that is incremental and calling to a certain degree of formalisation, standardisation and routine, hinders the introduction of more radical innovations (Prajogo and Sohal, 2001). If the role of TQM in preventing breakthrough innovation is quite controversial, it is relatively consensual that continuous improvement is needed to sustain the benefits resulting from innovation. In this sense, continuous improvement routines, highly supported by a range of quality tools, can act as a solid foundation on which to build an innovative organisation.

If we are to assess the relationship between TQM and innovation, we need to acknowledge the conflicting arguments that were just presented. More than a set of tools and techniques, TQM is a complex management philosophy. Because it encompasses "hard" and "soft" elements, which can be associated with somehow contrasted views of the organisation (mechanistic Versus organic), the overall impact of TQM on innovation is difficult to generalise. Previous research (Prajogo and Sohal, 2006a) tends to argue that if the mechanistic model prevails, TQM can be an important obstacle to innovation. On the other hand, if "soft" elements - closely linked to the organic model - are highly valued, TQM becomes in fact a strong driver of innovation.

In summary, when the implementation of quality principles and practices takes part within the organic model, TQM establishes a system and culture that will provide a fertile environment for organisations to innovate.

\section{Research goals and methodology}

To some extent, our research builds on that undertaken by Prajogo and Sohal (2001, 2004, 2006a, b) with the purpose of understanding the relevance of TQM in creating the right environment for companies to innovate.

People management practices and the organisational structure are common indicators of the way an organisation practices the TQM principles described above (see Section 2.1). In fact, customer focus, people involvement and continuous improvement call for decentralisation of decisions and information, vertical and horizontal communication, worker's autonomy and polyvalence, teamwork and the reduction of organisational hierarchical layers, among others.

Specifically, comparing to previous studies, we go a step further by addressing the following question:

- Is the implementation of TQM principles, assessed by certain people management practices, supporting innovation?

Accordingly, the organisational practices analysed are tentatively regarded as important enablers of the adoption of technological innovation.

An appropriate people management strategy is commonly associated to the successful integration of new technologies into the working environment (Baldwin and Johnson, 1996). This strategy should emphasise the development of good employee relations, training, full utilisation of employee skills and autonomy.

The organisational structure and the job characteristics must be aligned with the culture and people management strategies. Strong (and rigid) hierarchical structures are in general considered as detrimental, since they restrain the free flow of information and discourage collaboration and risk-taking attitudes. Similarly, highly centralised structures appear to inhibit innovation (Daft, 1978; Damanpour, 1991). On the contrary, teams and task forces, along with extensive interpersonal communication, by supporting integration and building connection among the staff, can be important structural enablers. 
The main goal is therefore to analyse the extent to which some TQM principles - the ones more clearly associated with the organic view of TQM - are supporting innovation in the Portuguese footwear industry.

Our study can also be seen as original from the point of view of the field where it is applied: it looks to a particular industry, one that can clearly be categorised as mature, and to a country where still limited research in this area exists.

\subsection{Research framework and hypothesis}

Having in mind the research goal abovementioned, and based on the arguments discussed on the previous sections, we have developed our theoretical framework as shown in Fig. 1.

As depicted in Fig. 1, autonomy, communication, consultation, flexibility and supportive people management practices were selected as the main dimensions to represent the TQM enablers of technological innovation (adoption). Each of the corresponding tentative constructs was translated into a set of measurement items (see Table 2).

Innovation, on its turn, can be divided into technological-product and process-and non-technological (i.e. organisational). At this point of our research, technological innovation only considers the process innovation dimension, regarded as changes in the way products and services are produced that result either in the possibility to produce larger amounts of output with the same resources or to obtain products/services with higher performance levels. Since the size of the Portuguese footwear firms is small, technological innovation is seldom carried out at the unitlevel, but rather results often from the cooperation among different actors. Thus, innovation is an interactive process, which, in this sector, has been strongly supported by

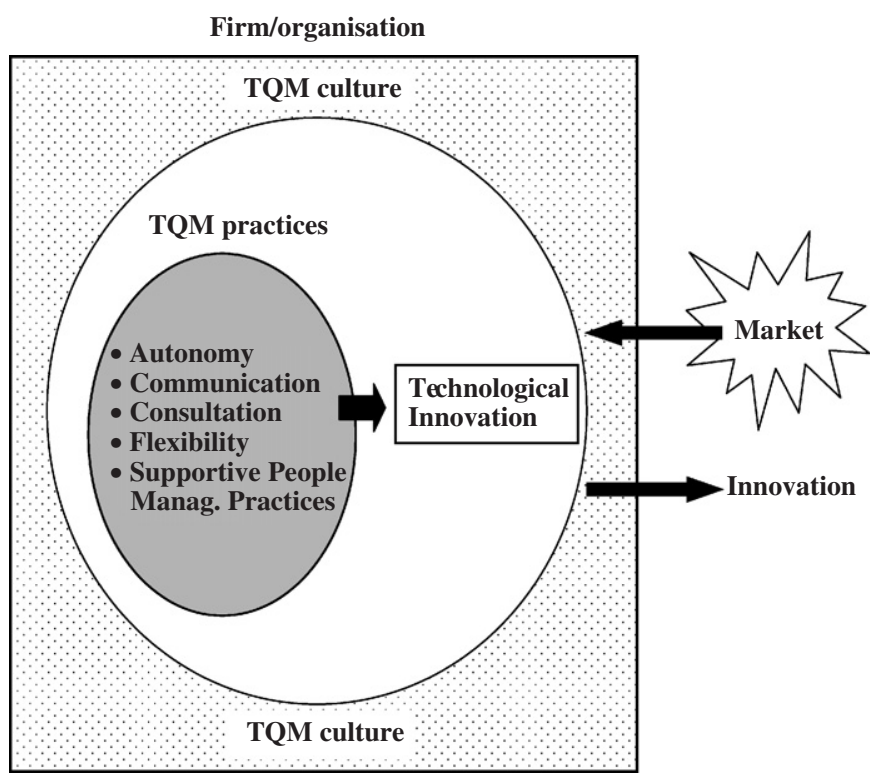

Fig. 1. Relationships between TQM and innovation (proposed theoretical framework).

Table 2

Proposed TQM enablers of innovation

\begin{tabular}{l} 
Tentative \\
constructs \\
\hline Autonomy \\
It relates to the \\
degree to which \\
employees have \\
some discretion \\
and control over \\
job-related \\
decisions
\end{tabular}

Internal communication It reflects the extent of communication among organisational units or groups

Consultation

It relates to the degree to which the organisation listens to its employees

\section{Qualitative}

flexibility

It concerns the firm's ability to adjust and deploy the skills of its employees to match the tasks required by its changing workload, production methods and/or technology.
Selected measurement Items

- A1: Authority to take immediate corrective actions once problems arise

- A2: Support from the supervisors to the decisions made

- A3: Active role in task planning and scheduling

- A4: Control over the quality of the work

- CO1: Degree of vertical (hierarchical) communication

- CO2: Degree of intradepartmental communication (among co-workers that belong to the same area)

- CO3: Degree of transversal (interdepartmental) communication

- CO4: Accessibility of upper manager to shopfloor workers

- C1: Employees' feedback collection through the use of questionnaires

- C1: Existence of a system to collect employees' suggestions

- C3: Disclosure of the results of the questionnaires

- C4: Workers' involvement in strategy decision making

- F1: Use of job rotation schemes

- F2: Development of competencies for workers to perform a wide variety of tasks

- F3: Implementation of the "cell manufacture" concept

- F4: Development of the workers' abilities to perform in "cells"

- F5: Specific vocational training (Reversed)

- F6: Selection of workers based on generic abilities (internal education and training gives them the competencies to perform specific tasks)
Roebuck (1996) EPOC (1997)

Subramanian and Nilakanta (1996) Damanpour (1991)

Saleh and Wang (1993)
Damanpour

(1991)

Thompson (1965)

Subramanian and Nilakanta (1996)

$\mathrm{Nahm}$ et al.

(2003)

Damanpour (1991)

Nahm et al. (2003) 
Table 2 (continued)

\begin{tabular}{|c|c|c|}
\hline $\begin{array}{l}\text { Tentative } \\
\text { constructs }\end{array}$ & Selected measurement Items & Literature \\
\hline $\begin{array}{l}\text { Supportive people } \\
\text { management } \\
\text { practices } \\
\text { It relates to } \\
\text { people } \\
\text { management } \\
\text { practices that are } \\
\text { supportive of the } \\
\text { introduction of } \\
\text { TQM principles. }\end{array}$ & $\begin{array}{l}\text { - SPMP1: Continuous } \\
\text { education and training } \\
\text { - SPMP2: Performance } \\
\text { appraisal schemes }\end{array}$ & $\begin{array}{l}\text { Flynn et al. } \\
(1994) \\
\text { Black and Porter } \\
(1996) \\
\text { Sila (2007) } \\
\text { CEC (1998, 2002) } \\
\text { Saleh and Wang } \\
\text { (1993) }\end{array}$ \\
\hline
\end{tabular}

agencies - such as the industrial association (APICCAPS) and the technological centre (CTC).

Given their relative importance for the footwear industry some innovation items in particular were considered (see Table 3 ). This list was validated by industry experts and the technicians of the CTC.

These innovations were all considered as incremental, given that we have adopted the global perspective in classifying innovations as radical or incremental (see Section 2.2). Many studies (e.g. Dewar and Dutton, 1986) use the impact of innovation on the adopting firm as the decisive criterion in this categorisation. However, since that means that the same innovation may be classified differently to different firms, the definition is situationspecific, and, consequently, difficult to operationalise (Dahlin and Behrens, 2005). Thus, we have focused on the general novelty of the technical content of innovation to the world in classifying our innovation items. The 1997-2004 period was considered appropriate for that analysis. As expected, all the items in Table 3 represent adaptations of technological innovations already in use in other countries/industries, and therefore must be considered as incremental.

In this study, we consider one single stage of the diffusion process of an innovation (as described by Rogers, 1995). In this sense, the adoption of a particular innovation item means that innovation is in use.

Innovativeness, by definition, is an enduring organisational trait. Truly innovative organisations are those that exhibit innovative behaviour consistently over time. Any valid measure of innovativeness must, therefore, capture this temporal dimension of innovativeness.

The number of innovations adopted by firms is an important sign of their innovativeness.

Some studies categorise firms as innovative firms if they adopt an innovation earlier than the majority of their industry counterparts. These studies distinguish early adopters of innovations from late adopters. Hence, the time of adoption of an innovation reflects the innovativeness of a firm.

Therefore, as suggested by Subramanian and Nilakanta (1996) and Damanpour and Gopalkrishnan (1998), in-
Table 3

Proposed technological (process) innovation items

- Automatic systems cutting samples

- Automatic conveyers with dynamic distribution and dynamic warehouses

- Digitalizing table for leather and other materials

- Automatic nesting system for leather and other materials

- Automatic leather cutting systems (WaterJet/Laser/knife)

- Engraving system by laser

- Automatic stitching machine

- Automatic toe lasting machine

- CAD system

novation adoption is a multidimensional construct and will be measured by two items:

- mean number of innovations adopted over time (MNI); and

- mean time of adoption of innovations (MTI).

For each item of Table 3, firms were asked to indicate whether or not they adopted it, the year of adoption and the importance they brought to their operations.

From the review of previous studies, our knowledge from case studies research, and in line with the theoretical framework presented in Fig. 1, the following hypotheses emerged:

H1. High levels of autonomy are associated with high levels of (technological) innovation adoption.

H2. High levels of communication are associated with high levels of (technological) innovation adoption.

H3. High levels of consultation are associated with high levels of (technological) innovation adoption.

H4. High levels of qualitative flexibility are associated with high levels of (technological) innovation adoption.

H5. High levels of supportive people management practices are associated with high levels of (technological) innovation adoption.

These hypotheses are summarised in Fig. 2.

\subsection{Source of empirical data}

During a 2-year period - from 2004 to 2005 - data was collected from multiple sources. In particular, archival data, interviews and direct observation were used in this process.

The extensive archival data included financial data, historical data and press releases related to individual firms, as well as media articles and industry studies.

Semi-structured interviews were conducted with internal and external informants. Internal informants included top and middle managers to whom we listened to with the aim 


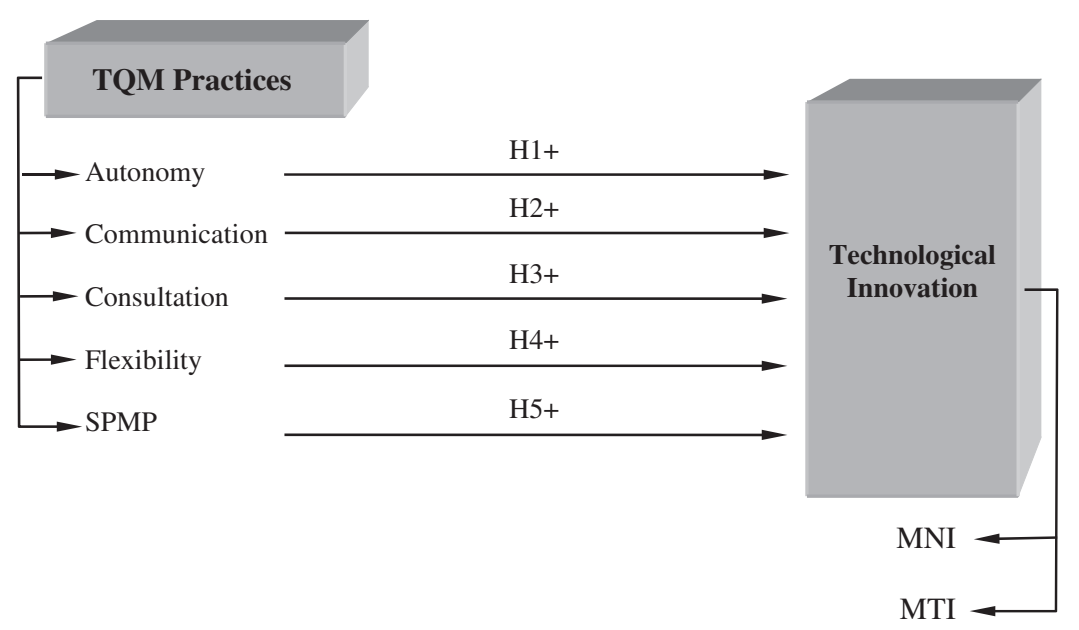

Fig. 2. TQM and process innovation (proposed relationships).

of getting acquainted with the firms' history, culture, strategy and the way they perceive and react to environmental changes. These interviews were complemented with extensive talks with external informants: business partners, competitors, and, in special, with industry experts. The majority of these experts were part of the FATEC project (a mobilising project funded by the EC structural funds for the footwear industry that involved several European universities and researchers). The role of these experts was critical in two key stages of the research: the design of the questionnaire and the interpretation of some results. In fact, it was possible to discuss the content and language of the questionnaire with the FATEC team, thus enhancing the validation of the instrument. Interviews administered to the top managers of the firms, together with the ones that we have conducted in the industrial footwear association (APICCAPS) and in the footwear technological centre (CTC) to members of the executive bodies, allowed us to understand the circumstances under which innovations are adopted and the main types of innovations introduced over the period of analysis. Additionally, the interaction with the experts facilitated the contact with the firms.

Direct observation took place within the visits to a sample of firms, where case studies were conducted. These visits, which lasted on average $3 \mathrm{~h}$, allowed us to observe the behaviours of managers, designers and production workers in the shopfloor. In particular, we observed internal management meetings conducted with the aim of analysing the firm's strategy and production quality issues, as well as meetings with outside partners such as suppliers, distributors and retailers. In some cases, we even conducted some participant observation working alongside the production workers and gaining in-depth understanding of the activities involved in the production process. We also participated in national and international industry fairs, where footwear firms promote and sell their products.

Finally, data was collected from a sample of twenty firms using a survey instrument. The questionnaire resulted from the knowledge of the field and from the review of other empirical studies, applied in different sectors and countries. The information gathered in the interviews and visits was essential to adapt the scales used to measure the different TQM practices and to find the most appropriate wording for the questions. The contribution of the experts was also very useful in the simplification of the instrument and in the administration of the pilot, which was carried out to preliminarily test the questionnaire in three firms. The resulting questionnaire covers the dimensions and measurement items shown in Table 2 and 3.

With regard to the measurement approach, perceptual data was used in which respondents were asked to evaluate the company's innovation performance and the level at which certain TQM principles - regarded as major innovation enablers-were practised (using a 5-point Likert scale). Data was also gathered concerning the innovation patterns (type of technology adopted, year of introduction, and its importance to the production process).

The questionnaire was administered face-to-face to the top managers of these firms. Administering the questionnaire face-to-face gave us more confidence that the respondents clearly understood the questions that were posed to them and also enabled the collection of additional comments thus enriching the data collection process.

The findings we report here take only into account the top managers' perceptions (one response per firm). It is important to notice that, although we have collected information concerning several kinds of employees, in this study we are only assessing the people management practices and work organisation principles used with regard to shopfloor employees.

The twenty firms that make up our sample belong to the CAE (Economic Activity Code) 19301-footwear manufacturers, are currently in-business and have at least 45 employees, regarded as the minimum size to apply the management principles addressed in this research.

The surveyed firms are located in the North of Portugal in the regions of S. João da Madeira (65\%), Felgueiras 
$(30 \%)$ and Guimarães (5\%), where the vast majority of the footwear firms traditionally have their production plants. More than $50 \%$ of the firms surveyed had, at the time this research was conducted, between 50 and a 100 employees, about $30 \%$ employed between 101 and 200 people, around $5 \%$ had between 201 and 500 workers, and approximately $10 \%$ had more than 500 employees.

\subsection{Data analysis}

Five constructs (autonomy, communication, consultation, qualitative flexibility, and supportive people management practices) represent the TQM principles selected in this study. This TQM constructs were subjected to validity and reliability tests.

Establishing reliability and validity is essential to ensure that the scales actually measure the concepts they are supposed to represent (Sureshchandar et al., 2001).

The first main concern is to ensure adequate coverage of the domain of each concept (content validity). The evidence of content validity is purely subjective and logical rather than statistical. Therefore, in order to ensure content validity, the items (or manifest variables) representing each construct were substantiated by a comprehensive review of the literature (see Table 2).

The reliability analysis was conducted by calculating the Cronbach's alpha for each scale. According to Churchill (1979, cited in Bontis, 1998), Cronbach's alpha should be the first measure to be employed to assess the quality of a measurement instrument. The results show (see Table 4) that the Cronbach's alpha measure for the five constructs satisfactorily meet the minimum criterion of 0.7 (Hair et al., 1998), hence, establishing their reliability.

Next, the scales were inspected for convergent and discriminant validity. Convergent validity is an assessment of the consistency in measurements across multiple operationalisations (different attempts to measure the same construct should be in agreement), while discriminant validity refers to the degree to which measures of different dimensions are unique from each other and is demonstrated when a measure does not correlate very highly with another measure from which it should differ (Venkatraman, 1989). Discriminant-validity analysis shows the extent to which a scale is new and not just a reflex of other variables (Hulland, 1999; Robledo, 2001).
Important indications can be found in the correlation between the scales. When a measure correlates well with other measures that are believed to measure the same construct, evidence for convergent validity is obtained. Weak correlations between measures that are theoretically distinct demonstrate discriminant validity (Sureshchandar et al., 2001). Correlations and Cronbach-alpha coefficients were used in this research as indirect indicators of convergent validity, since they reflect the degree of cohesiveness among the scale items.

Table 4 also provides evidence of the convergent and divergent validity of the scales. As Ghiselli et al. (1981, cited in Flynn and Saladin, 2001) suggests, two approaches were used. First, the Cronbach reliability coefficient for each scale was compared with the average of its correlations with other constructs. Since all scales have higher homogeneity coefficients than their average correlations with the other scales, discriminant validity is established. Second, the analysis of item-to-total correlations (see the last two columns of Table 4) shows that on average items that belong to the same construct have higher correlations among them than they do with the ones that form other scales. Together, this strongly suggests that the various items do indeed load in the appropriate constructs.

To complement the assessment of the constructs validity, and given the high correlations among the items, as recommended by several authors (e.g. González-Alvarez and Nieto-Antolín, 2007), a principal component analysis was performed.

As shown in Table 5, the Kaiser-Meyer-Olkin test for the various scales presents a value above 0.5 , thus revealing that the samples are appropriate for factor analysis. This is corroborated by the Bartlett's test, which in every case, leads to the rejection of the null hypothesis.

For all scales, it is possible to observe that we extracted only one component with an eigenvalue above one, thus showing that the suggested scales are unidimensional In addition, all the extracted factors account for more than $50 \%$ of the variance. It is worthwhile to mention that the flexibility construct (see Table 2) was refined during this process. Indeed, in the first iteration, two factors were obtained that we labelled, according to the respective factor loadings, as rotation and teamwork. This might be explained by the fact that flexibility is still a relatively broad concept thus showing a relatively lower degree of

Table 4

Scale validation results

\begin{tabular}{llllll}
\hline Constructs & No. items & Cronbach alpha & $\begin{array}{l}\text { Average inter-scale } \\
\text { correlation }\end{array}$ & \multicolumn{2}{c}{\begin{tabular}{l} 
Average item correlations \\
\cline { 4 - 6 }
\end{tabular}} \\
& & & & Scale items \\
\hline Autonomy & 4 & 0.74 & 0.29 & 0.46 & 0.22 \\
Communication & 4 & 0.91 & 0.17 & 0.75 & 0.17 \\
Consultation & 4 & 0.86 & 0.37 & 0.50 & 0.24 \\
Teamwork & 2 & 0.96 & 0.32 & 0.92 & 0.04 \\
SPMP & 2 & 0.74 & 0.12 & 0.60 & 0.08 \\
\hline
\end{tabular}


Table 5

Factorial analysis results

\begin{tabular}{|c|c|c|c|c|}
\hline \multirow[t]{2}{*}{ Component } & \multirow[t]{2}{*}{ Eigenvalue } & \multirow[t]{2}{*}{$\%$ of variance } & \multicolumn{2}{|c|}{ Component matrix retained } \\
\hline & & & Item* & Component 1 \\
\hline \multicolumn{5}{|c|}{ Autonomy $($ KMO test $=0.602)$} \\
\hline 1 & 2.263 & 56.574 & A1 & 0.678 \\
\hline 2 & 0.979 & 24.469 & $\mathrm{~A} 2$ & 0.889 \\
\hline 3 & 0.508 & 12.702 & A3 & 0.726 \\
\hline 4 & 0.250 & 6.255 & A4 & 0.697 \\
\hline \multicolumn{5}{|c|}{ Communication $($ KMO test $=0.751)$} \\
\hline 1 & 3.242 & 81.048 & $\mathrm{CO} 1$ & 0.900 \\
\hline 2 & 0.453 & 11.332 & $\mathrm{CO} 2$ & 0.957 \\
\hline 3 & 0.221 & 5.529 & $\mathrm{CO} 3$ & 0.872 \\
\hline 4 & 0.084 & 1.090 & $\mathrm{CO} 4$ & 0.869 \\
\hline \multicolumn{5}{|c|}{ Consultation $($ KMO test $=0.654)$} \\
\hline 1 & 2.878 & 71.938 & $\mathrm{C} 1$ & 0.926 \\
\hline 2 & 0.672 & 16.806 & $\mathrm{C} 2$ & 0.879 \\
\hline 3 & 0.376 & 9.395 & $\mathrm{C} 3$ & 0.833 \\
\hline 4 & 0.074 & 1.862 & $\mathrm{C} 4$ & 0.745 \\
\hline \multicolumn{5}{|c|}{ Teamwork $($ KMO test $=0.500)$} \\
\hline 1 & 1.921 & 96.057 & F3 & 0.980 \\
\hline 2 & 0.079 & 3.943 & F4 & 0.980 \\
\hline \multicolumn{5}{|c|}{ Supportive people management practices $($ KMO test $=0.500)$} \\
\hline 1 & 1.921 & 96.057 & SPMP1 & 0.980 \\
\hline 2 & 0.079 & 3.943 & SPMP2 & 0.980 \\
\hline
\end{tabular}

*See Table 2

Principal component analysis results (confirmatory study).

homogeneity among the items chosen to measure it. We decided to keep only teamwork for the upcoming analysis. In fact, during the fieldwork we realised that rotation was often circumscribed to a reduced number of shopfloor employees. Therefore, we anticipated that this driver would have a limited impact in the firms.

Moreover, looking at the factor loadings, one can affirm that all the retained measurement items are relevant to the corresponding factors (Table 5), thus indicating that the various questionnaire items do indeed load in the appropriate construct.

Having met the requirement of construct validity and reliability, the composite value for each construct can be calculated and the multiple regression analysis performed. The main results will be shown and discussed in the next section.

\section{Results and discussion}

The implementation level of the TQM principles considered in this study is relatively low, ranging from 2.2 to 3.8 (see Table 6). Note that, among several methods suggested by Hair et al. (1998), the mean value was selected to represent the composite variables due to the simplicity of the method without forfeiting the accuracy.

The results presented in Table 6 are not surprising given the characteristics of the Portuguese footwear industry, where TQM initiatives are still immature, especially in
Table 6

The implementation level of the TQM principles

\begin{tabular}{llll}
\hline Constructs & No. items & Mean (out of 5) & S.D. \\
\hline Autonomy & 4 & 2.89 & 0.80 \\
Communication & 4 & 3.83 & 0.94 \\
Consultation & 4 & 2.39 & 1.05 \\
Teamwork & 2 & 2.55 & 1.00 \\
SPMP & 2 & 2.26 & 1.21 \\
\hline
\end{tabular}

what concerns its "soft elements". In fact, the proportion of the firms that obtained any kind of ISO 9000 certification (that, despite the criticisms that the formality of the process, is often regarded as an indication of the commitment to quality management) is still very low, even if the exporting nature of the industry may add pressure to obtaining a formal recognition of the existence of a quality management system. In fact, most Portuguese footwear firms only very recently started to feel the pressure from the market (and their customers) to obtain such recognition. Many, work as manufacturer subcontractors to the medium segment, where, typically, customers are not very demanding in this regard. It is interesting to notice that, among the firms that participated in our study, the single one that is already certified and the few others which are at the moment going through the certification process are simultaneously those that are trying to build/reinforce their brands.

Moreover, the fieldwork conducted in the firms clearly reveals that very few people have any kind of training in quality principles, tools or methodologies. Quality efforts are seldom transversal in the organisations and the responsibilities for the establishment of quality goals are very ill-defined. In general, there is no structure specifically dedicated to quality management. The exceptions are the firms with a strong internationalisation focus (multinational).

Thus, Quality is, in general, confined to the visual inspection of the final products with the aim of identifying defects and other non-conformities. Process monitoring is still very scarce with an almost absence of the use of control charts. The root causes of the problems are often not identified and a fire-fighting attitude prevails. Internal accounting systems (when they exist) do not allow for the knowledge of quality (and non-quality) costs.

In this scenario, quality practices are almost exclusively informal, with a lack of resources assigned to them, and generally regarded as "extra workload".

An additional explanation to the low level of the implementation of TQM practices can be found in the fact that most firms are family owned (micro- and small firms represent $85 \%$ of the industry (PROINOV, 2001, p. 31)), have a familiar structure, highly centralised in the person who is at the top (most of the times the founder), and where the large majority of the workers - around $65 \%$, according to the CTC $(2004$, p. 29) - have low levels of 
education and qualification. The firms' organisational structures - strongly functional - and the level of qualifications of both managers and employees - most of them without a secondary degree and with a lifetime experience in the industry - are important obstacles to the diffusion of TQM, and, in particular, to the adoption of the management practices that it requires. That explains, for example, why the level of consultation is so low. Managers are not willing to share their decision power, as the average of the item "active role (of employees) in task planning and scheduling" (2.1) shows. On the other hand, the relatively small size of the firms makes communication easier, especially with regard to the vertical flows of information (4.2).

Regarding the innovation profile of the Portuguese firms analysed, one can affirm that they are not very innovative. In fact, the MNI for the sample is 0.41 , which means that, on average, each firm adopts less than one innovation per year. The MTI, which represents the number of years that, in average, each firm has adopted innovations earlier than the last adopting firm, for the sample is 1.66 years. Thus, the time gap is relatively small, meaning that the firms have adopted the innovations considered almost at the same time.

The relationships among the various TQM and innovation constructs, assessed by the corresponding partial correlations, are presented in Table 7.

As expected, the correlations among the TQM principles are positive and, in many cases, statistically significant, emphasising its holistic nature. This goes in line with previous studies (e.g. Prajogo and Sohal, 2006b). Thus, the TQM principles reinforce each other and the philosophy must be applied as a whole.

Moreover, the high correlation between MNI and MTI reveals that the firms that have introduced more innovations in the time period considered are simultaneously the ones that can be considered early adopters.

Regarding the correlations between the TQM practices and the innovation measurements, most correlations are not significant. However, by itself, this analysis is not very insightful and must be complemented with the use of more appropriate statistical techniques. Taking into consideration the characteristics of our sample, the multiple regression analysis was chosen. In this process, we decided to use the MNI as the dependent variable (in fact, the high correlation between MNI and MTI-mean time of innovation adopted -indicates that a similar estimation using MTI would not add much qualitative insights into the research question under study).

The following model was estimated:

$$
\begin{aligned}
M N I= & \alpha+\beta_{1} A U T O N+\beta_{2} \text { COMMUN }+\beta_{3} \text { CONSULT } \\
& +\beta_{4} \text { TEAMWORK }+\beta_{5} \text { SPMP. }
\end{aligned}
$$

The regression coefficients, as well as the respective significance levels, are shown in Table 8.

As indicated in the previous table, the regression coefficients give support to three out of the five hypotheses we put forward (see Fig. 2). Furthermore, the model has a very reasonable fit, as the $R^{2}$ of $35 \%$ indicates. In fact, it must be acknowledged that innovation processes in firms are influenced by multiple factors, some of them even exogenous to the firms.

Supporting our propositions, communication, supportive people management practices and teamwork have a positive and significant impact on innovation adoption. $\mathrm{H} 2, \mathrm{H} 4$ and $\mathrm{H} 5$ are therefore confirmed. In line with most studies in this research field, the Portuguese firms surveyed might use these principles as innovation drivers.

Contrarily to our expectations, autonomy and consultation are negatively associated (although not significantly) with process innovation adoption. Yet, reflecting upon the reality of the Portuguese footwear firms at the shopfloor level, it is possible to find an explanation to the (apparently confusing) fact. Indeed, although most studies regard centralisation as an organisational constraint to innovation adoption (Damanpour, 1991; Nohria and Gulati, 1996), some others (e.g. Dewar and Dutton, 1986) obtained, in accordance to our research, results that contradict the dominant thought. In effect, centralisation of decisions and power might help to overcome the organisational inertia to change. This might be even more applicable to the Portuguese case, where production workers mainly follow orders and carry out specialised tasks within specified positions, making the managers possibility to use autonomy very limited and the impact of listening skills on innovation adoption low. This is reinforced by the low level of qualifications of these

Table 7

Correlation matrix among the latent constructs and the innovation indexes

\begin{tabular}{lcccccr}
\hline & Auton & Consult & SPMP & Teamwork & Commun & NMI \\
\hline Auton & 1.00 & $0.510^{* *}$ & 0.159 & -0.036 & $0.512^{* *}$ & -0.117 \\
Consult & $0.510^{* *}$ & 1.00 & 0.329 & 0.243 & $0.393^{*}$ & -0.043 \\
SPMP & 0.159 & 0.329 & 1.00 & 0.080 & -0.075 & -0.243 \\
Teamwork & -0.036 & 0.243 & 0.080 & 1.00 & -0.160 & 0.288 \\
Commun & $0.512^{* *}$ & $0.393^{*}$ & -0.075 & -0.160 & 1.00 & 0.270 \\
NMI & -0.117 & -0.043 & 0.288 & 0.270 & 0.133 & 0.133 \\
TMI & -0.243 & -0.139 & 0.305 & 0.336 & -0.092 & 0.336 \\
\hline
\end{tabular}

$* * * p<0.01 ; * * p<0.05 ; * p<0.10$. 
Table 8

Multiple regression analysis results

\begin{tabular}{|c|c|c|c|c|}
\hline & $\beta$ & $t$ & Sig. & Hypothesis \\
\hline Autonomy & -0.247 & -0.864 & 0.403 & H1. Not supported \\
\hline Communication & 0.495 & 1.752 & 0.103 & H2. Supported at 0.1 significant level \\
\hline Consultation & -0.355 & -1.18 & 0.258 & H3. Not supported \\
\hline Teamwork & 0.391 & 1.610 & 0.131 & H4. Supported at 0.15 significant level \\
\hline SPMP & 0.450 & 1.830 & 0.090 & H5. Supported at 0.1 significant level \\
\hline
\end{tabular}

$R^{2}=0.346$

Adjusted $R^{2}=0.094$.

Estimated model: $M N I=\alpha+\beta_{1}$ AUTON $+\beta_{2}$ COMMUN $+\beta_{3}$ CONSULT $+\beta_{4}$ TEAMWORK $+\beta_{5} S P M P$

workers, which possibly inhibits them to take initiative and assume risks.

Besides, previous studies did not statistically confirm some of the relationships potentially linking TQM principles to innovation adoption (e.g. Singh and Smith, 2004). In general, they either suggest that TQM on its own is not a sufficient driver of innovation and must be complemented with other resources (Prajogo and Sohal, 2006b, 2003).

In any case, the comparison of different studies results must be done cautiously, since the way innovation and TQM dimensions are defined and measured, as well as the methodologies applied, are not uniform.

\section{Conclusion}

This paper has investigated the role of TQM in supporting innovation in the Portuguese footwear sector, which is clearly a traditional and mature industry. As an industry that is facing a process of dynamic transformation, it must look for new competitive factors to maintain and gain competitiveness in the new global market. In this regard, technology by itself may not be sufficient. It must be complemented with new forms of innovation, namely organisational innovation, which is associated with the implementation of the "soft" elements of TQM.

Yet, the relationship between TQM and innovation is rather controversial, as several previous studies indicate: the impact of different TQM dimensions in the various types of innovation is difficult to generalise. In this sense, we have concentrated on those TQM elements that are potentially more supportive of the kind of innovation that applies to the industry under analysis (incremental technological/process innovation).

As our findings indicate, TQM is a holistic philosophy that calls for the simultaneous implementation of its key principles. The correlations found among its elements are high, suggesting that they complement each other.

The results obtained in this study tend to support most of our proposed relationships between the TQM dimensions chosen and (technological) innovation. Thus, the hypotheses concerning the impact of communication, teamwork and supportive people management practices on innovation were confirmed. In the remaining cases, the strength of the relationships was low, making the regres- sion coefficients not statistically significant. Yet, it is important to notice that the relatively weak associations between certain TQM dimensions and innovation adoption do not imply that those principles do not play an important role in driving innovation. Moreover, the Portuguese footwear industry is still dominated by the features of the mechanistic model (e.g. high centralisation, functional structure, vertical hierarchy, specialisation), mainly at the shopfloor level, even if there are some signs of the introduction of certain practices that belong to the organic paradigm (e.g. communication, shared beliefs, polyvalence).

It is our belief, corroborated by our fieldwork, that as the level of implementation of TQM principles increases, firms will be more prepared to innovate on a regular basis. In particular, TQM principles are regarded as important enablers of the "real" implementation of the innovations adopted and of their absorption within the firm.

Our study has several limitations. First, by being concentrated in a particular industry, it is unclear to what extent our findings can be generalised. Second, it relies on perceptual data from top managers only and might not give a complete picture of the organisation. In both cases, future studies, conducted in other industries and based on multiple respondents, may shed additional light into the matters.

Finally, our study has interesting implications for policy and practice. If firms in mature manufacturing industries, operating in developed countries, are to survive and thrive in face of low cost competition from emerging economies, technological innovation must be complemented and supported by organisational innovation. Our findings give support to the importance of TQM principles as drivers of technological innovation. It follows that the adoption of certain organisational principles need to be encouraged and, therefore, part of national and Community funds to innovation should be allocated to the diffusion of new management principles.

\section{Acknowledgements}

The authors gratefully acknowledge the financial support provided by the FATEC (Footwear Advanced Technologies) funded by the Portuguese Government. The authors also thank the collaboration of the Portuguese Footwear Technological Centre. 


\section{References}

Ahire, S.L., Waller, M.A., Golhar, D.Y., 1996. Quality management in TQM versus non-TQM firms: an empirical investigation. International Journal of Quality and Reliability Management 13 (8), 8-27.

APICCAPS, 2003. A Indústria Portuguesa de Calçado e Artigos de Pele. Publicações APICCAPS, Porto.

Arrow, K.J., 1962. The economic implications of learning by doing. Review of Economic Studies 29 (3), 155-173.

Atuahene-Gima, K., 1996. Market orientation and innovation. Journal of Business Research 35, 93-103.

Baldwin, J., Johnson, J., 1996. Business strategies in more-and lessinnovative firms in Canada. Research Policy 25, 785-804.

Black, S., Porter, L., 1996. Identification of the critical factors of TQM. Decision Sciences 27 (1), 1-20.

Bontis, N., 1998. Intellectual capital: an exploratory study that develops measures and models. Management Decision 36 (2), 63-76.

Cameron, K., Barnett, C., 2000. Organizational quality as a cultural variable. In: Cole, R., Richard, W. (Eds.), The Quality Movement \& Organization Theory. Sage Publications, Beverly Hills, CA, pp. 271-294.

CEC, 1995, Green Paper on Innovation, COM (95) 688, December 1995, available at $\langle$ http://europa.eu.int/en/record/green/gp9512/ind_inn.htm $\rangle$.

CEC, 1998. New Forms of Work Organisation: Case Studies. DG Employment, Industrial Relations and Social Affairs, Bruxels.

CEC, 2002. New Forms of Work Organisation: the Obstacles to Wider Diffusion. DG Employment and Social Affairs, Bruxels.

CTC, 2004. Utilização da formação como factor de competitividade pelas empresas da fileira do calçado. Estudos e Investigação, Centro Tecnológico do Calçado.

Daft, R.L., 1978. A dual-core model of organizational innovation. Academy of Management Journal 21, 193-210.

Daft, R.L., 1982. Bureaucratic versus nonbureaucratic structure and the process of innovation and change. In: Bacharach, S.R. (Ed.), Research in the Sociology of Organizations. JAI Press, Greenwich, CT.

Dahlin, K.B., Behrens, D.M., 2005. When is an innovation really radical? Defining and measuring technological radicalness. Research Policy 34, 717-737.

Dale, B.G., Cooper, C., Wilkinson, A., 1997. Managing Quality \& Human Resources: A Guide to Continuous Improvement. Blackwell, Oxford, UK.

Damanpour, F., 1991. Organisational innovation: a meta-analysis of effects of determinants and moderators. Academy of Journal Management 34 (3), 555-590.

Damanpour, F., Gopalkrishnan, S., 1998. Theories of organizational structure and innovation adoption: the role of environmental change. Journal of Engineering Technology and Management 15, 1-24.

Dean, J., Bowen, D.E., 1994. Management theory and total quality improvement: research and practice through theory development. The Academy of Management Review 19 (3), 392-418.

Dewar, R.D., Dutton, J.E., 1986. The adoption of radical and incremental innovations: an empirical analysis. Management Science 32 (11), 1422-1433.

EPOC, 1997. New Forms of Work Organisation: Can Europe Realise its Potential? Results of a Survey of Direct Employee Participation in Europe. European Foundation for the Improvement of Living Conditions, Dublin.

Flynn, B., Saladin, B., 2001. Further evidence on the validity of the theoretical models underlying the Baldrige criteria. Journal of Operations Management 19, 617-652.

Flynn, B., Schroeder, R., Sakakibara, S., 1994. A framework for quality management research and an associated measurement instrument. Journal of Operations Management 11, 339-366.

Freel, M., 2003. Sectoral patterns of small firm innovation, networking and proximity. Research Policy 32 (5), 751-770.

Freeman, C., Perez, C., 1988. Structural crisis of adjustment, business cycles and investment. In: Dosi, G., Freeman, C., Nelson, R., Silverberg, G., Soete, L. (Eds.), Technical Change and Economic Theory, second ed. Pinter Publishers, London, pp. 38-66.
Gilbert, J., 1994. Choosing an innovation strategy: theory and practice. Business Strategies (November/December), 16-22.

Grant, R., Shani, R., Krishnan, R., 1994. TQM's challenge to management theory and practice. Sloan Management Review (Winter), 25-35.

González-Álvarez, N., Nieto-Antolín, M., 2007. Appropriability of innovation results: an empirical study in Spanish manufacturing firms. Technovation 27 (5), 280-295.

Hackman, J., Wageman, R., 1995. Total quality management: empirical, conceptual, and practical issues. Administrative Science Quarterly 40 (2), 309-342.

Hair, J., Anderson, R., Tatham, R., Black, W., 1998. Multivariate Data Analysis, fifth ed. Prentice-Hall, UK.

Hulland, J., 1999. Use of partial least squares (PLS) in strategic management research: a review of four recent studies. Strategic Management Journal 20, 195-204.

Jackson, M., 1991. Social systems theory and practice: the need for a critical approach. In: Flood, R., Jackson, M. (Eds.), Critical Systems Thinking. Wiley, Chichester, pp. 117-137.

Kanji, G.K., 2002. Measuring Business Excellence. Routledge Advances in Management and Business Studies, Routledge, London, UK.

Lundvall, B.- $\AA$., 1985. Product Innovation and User-Producer Interaction. Aalborg University Press, Aalborg.

Mcadam, R., 2000. Three leafed clover: TQM, organisational excellence and business improvement. The TQM Magazine 12 (5), 314-320.

Mcadam, R., 2004. Knowledge creation and idea generation: a critical quality perspective. Technovation 24, 697-705.

Mehra, S., Hoffman, J., Sirias, D., 2001. TQM as a management strategy for the next millennia. International Journal of Operations \& Production Management 21 (5/6), 855-876.

Molina, L.M., Lloréns-Montes, J., Ruiz-Moreno, A., 2007. Relationship between quality management practices and knowledge transfer. Journal of Operations Management 25 (3), 682-701.

Moreno-Luzón, M., Peris, F., 1998. Strategic approaches, organizational design and quality management: integration in a fit and contingency model. International Journal of Quality Science 3 (4), 328-347.

Nahm, A.Y., Vonderembse, M.A., Koufteros, X.A., 2003. The impact of organisational structure on time-based manufacturing and plant performance. Journal of Operations Management 21, 281-306.

Nohria, N., Gulati, R., 1996. Is slack good or bad for innovation? Academy of Management Journal 39, 1245-1264.

Prajogo, D., Sohal, A., 2001. TQM and innovation: a literature review and research framework. Technovation 21 (9), 539-558.

Prajogo, D., Sohal, A., 2003. The relationship between TQM practices, quality performance, and innovation performance: an empirical examination. International Journal of Quality \& Reliability Management 20 (8), 901-918.

Prajogo, D., Sohal, A., 2004. The multidimensionality of TQM practices in determining quality and innovation performance: an empirical examination. Technovation 24 (6), 443-453.

Prajogo, D., Sohal, A., 2006a. The relationship between organization strategy, total quality management (TQM), and organization performance: the mediating role of TQM. European Journal of Operational Research 168, 35-50.

Prajogo, D., Sohal, A., 2006b. The integration of TQM and technology/ R\&D management in determining quality and innovation performance. Omega 34, 296-312.

PROINOV, 2001. O Cluster do Calçado em Portugal. PROINOV.

Robledo, M.A., 2001. Measuring and managing service quality; integrating customer expectations. Managing Service Quality 11 (1), 22-31.

Roebuck, C., 1996. Constructive feedback: key to higher performance and commitment. Long Range Planning 29 (3), 328-336.

Rogers, E.M., 1995. Diffusion of Innovations, Fourth edition. The Free Press, New York.

Rosenberg, N. (Ed.), 1982. Inside the Black Box: Technology and Economics. Cambridge University Press, London.

Sá, P., Abrunhosa, A., 2007. The role of TQM practices in technological innovation: the Portuguese footwear industry case. Total Quality Management \& Business Excellence 18 (1-2), 57-66. 
Saleh, S.D., Wang, C.K., 1993. The management of innovation: strategy, structure, and organizational climate. IEEE Transactions on Engineering Management 40 (1), 14-21.

Saraph, J., Benson, G., Scroeder, R., 1989. An instrument for measuring the critical factors of quality management. Decision Science 20, 810-829.

Sila, I., 2007. Examining the effects of contextual factors on TQM and performance through the lens of organizational theories: an empirical study. Journal of Operations Management 25, 83-109.

Singh, P.J., Smith, A., 2004. Relationship between TQM and innovation: an empirical study. Journal of Manufacturing Technology Management 15 (5), 394-401.

Spencer, B., 1994. Models of organization and total quality management: a comparison and critical evaluation. Academy of Management Review 19 (3), 446-471.

Subramanian, A., Nilakanta, S., 1996. Organisational innovativeness: exploring the relationship between organizational determinants of innovation, types of innovations, and measures of organisational performance. Omega - International Journal of Management Science 24 (6), 631-647.

Sureshchandar, G.S., Rajendran, C., Anantharaman, R., 2001. A holistic model for total quality service. International Journal of Service Industry Management 12 (4), 378-412.

Thompson, V.A., 1965. Bureaucracy and innovation. Administrative Science Quarterly 10, 1-20.

United Nations, 2003. International Trade Statistics Yearbook, New York.

Venkatraman, N., 1989. Strategic orientation of business enterprises: the construct, dimensionality, and measurement. Management Science 35 (8), 942-962.

Wycoff, J., 2003. The big 10 innovation killers: how to keep your innovation system alive and well. Journal for Quality \& Participation 26 (2), 17-22. 